\title{
Late onset of amiodarone-induced thyrotoxicosis causing pharmacoresistant atrial fibrillation with subsequent development of serious heart failure
}

Nývltová M., Drbalová K., Vodák M., Krejčí P., Zavoral M.

Department of Internal Medicine of First Faculty of Medicine of Charles University and Military University Hospital, Prague, Czech Republic

Introduction:

Amiodarone is a potent and still very popular anti-arrhythmic drug in cardiology. This case report describes severe course of amiodarone-induced thyrotoxicosis (AIT) which is one of the most serious side effects of the treatment.

\section{Case report :}

The patient (J.S., female, born in 1950) was hospitalized in Central Military Hospital in Prague first in June 2012 for atrial fibrillation with rapid ventricular response. The echocardiography showed tachycardia-induced cardiomyopathy (TIC) with decreased ejection fraction (EF) of the left ventricle to $30 \%$. Thyroid hormones were normal at that time (TSH $1.77 \mathrm{mIU} / \mathrm{l}$, free T4 $9.14 \mathrm{pmol} / \mathrm{l}$, free T3 $5.1 \mathrm{pmol} / \mathrm{l}$ ). Collaborating cardiologist added amiodarone to the medication. The treatement was discontinued 6 month later due to symptomatic corneal deposits and it was replaced by dronedarone in combination with beta-blocker.

The second hospitalisation for the same reason was in September 2013. Thyrotoxicosis was diagnosed according to the laboratory findings (TSH under a detection limit $(0.005 \mathrm{mlU} / \mathrm{l})$, free T4 $44.8 \mathrm{pmol} / \mathrm{l}$, free T3 $13.9 \mathrm{pmol} / \mathrm{l})$. An ultrasound of the neck was performed $(11 \mathrm{ml}$ right lobe, $7 \mathrm{ml}$ left lobe, diffusely decreased echogenity and inhomogeneous structure, the arterial flow measured by doppler was low $(11 \mathrm{~cm} / \mathrm{s}))$. The scintigraphy with pertechnetate showed diffusely decreased accumulation. These findings confirmed the diagnosis of a destructive AIT. Further course of treatement and levels of thyroid hormones are in the graph below.

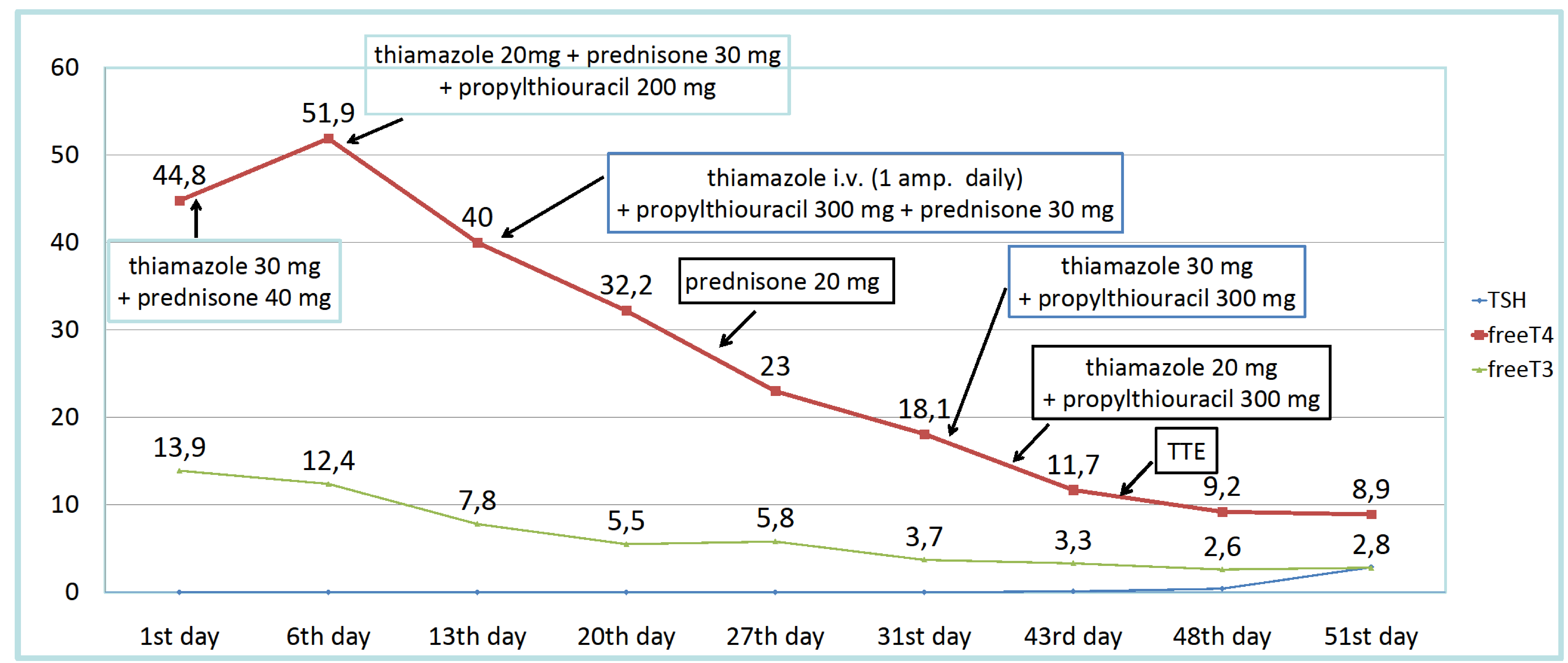

Despite normalized levels of thyroid hormones (33th day of treatement) the clinical condition began to deteriorate. The patient was short of breath, had a chest pain and palpitations (heart rate was $140 / \mathrm{min}$ ). She had to be moved to intensive care unit with a serious heart failure. After an administration of levosimendan, diuretics and after an electric cardioverison the clinical condition began to improve.

\section{Decision:}

\section{Because of a reccurent pharmacoresistant atrial fibrillation resulting in a serious heart failure} responding only to amiodarone, we decided to perform a total thyroidectomy (TTE). It was carried out 45th day of hospitalization at the ENT (Ear, Nose, Throat) Department without complications. Thyreostatic and corticosteroid treatement was discontinued and we initiated the substitution therapy (levothyroxin). Before the discharge the systolic function has improved (EF 40\%) and after 6 months it has normalized completely.
Conclusion:

This case report draws attention to the risk of developing a serious AIT even after a long time from the treatement discontinuation - in our patient more than half a year after the withdrawal of the drug. It was necessary to use combination therapy of antithyroid drugs (thiamazol, propylthiouracil) at higher doses (including parenteral administration form) together with corticosteroids. Due to a high risk of another episodes of atrial fibrillation with rapid ventricular response and heart failure, which did respond only to amiodarone, we have indicated a total thyroidectomy. This decision proved to be correct, because the arrhytmia reccured within a year. Without any major concern it was quickly pharmacologically reverted using amiodarone. Currently, amiodarone treatment was discontinued, the patient holds sinus rhythm and radiofrequency ablation is planned. 